\title{
TINGKAT KEPATUHAN PENGGUNAAN OBAT FENITOIN PADA PASIEN EPILEPSI DI RUMAH SAKIT CITRA SARI HUSADA INTAN BAROKAH KARAWANG
}

\author{
Maulana Yusuf Alkandahri*, Isra Qurrata Ayun Eka Putri \\ Prodi Farmasi, Fakultas Farmasi, Universitas Buana Perjuangan Karawang, Karawang, \\ Jawa Barat, Indonesia
}

J1. HS. Ronggowaluyo Telukjambe Timur, Karawang 41361 *Penulis Koresponding: maulana.yusuf@ubpkarawang.ac.id

\begin{abstract}
ABSTRAK
Epilepsi merupakan salah satu penyakit otak yang sering ditemukan di dunia. Data World Health Organization (WHO) menunjukkan epilepsi menyerang 70 juta dari penduduk dunia. Penyakit kronis adalah gangguan atau penyakit yang berlangsung lama (berbilang bulan atau tahun), seperti hipertensi, diabetes melitus, kusta, epilepsi, TBC, AIDS, leukimia, dan sebagainya. Penelitian ini bertujuan untuk mengetahui hubungan tingkat kepatuhan minum obat dengan jenis kelamin dan tingkat pendidikan terhadap angka kejadian penyakit epilepsi dengan penggunaan obat antihepilepsi pada pasien epilepsi di Instalasi Rawat Jalan Rumah Sakit Citra Sari Husada Intan Barokah Karawang periode Agustus-November 2020. Penelitian ini bersifat observasional dengan menggunakan rancangan analisis deskriptif cross-sectional. Pengumpulan data dilakukan secara prospektif dan retrosprektif dengan menggunakan data skunder berupa resep pasien epilepsi dan data primer berupa kuesioner yang diberikan kepada pasien rawat jalan di Rumah Sakit Citra Sari Husada Intan Barokah Karawang periode Agustus-November 2020. Penelitian ini dilakukan dengan cara menyebar kuesioner pada responden yang telah memenuhi kriteria inklusi. Diperoleh data sebanyak 96 pasien epilepsi yang menjadi responden. Hasil penelitian ini menunjukkan bahwa tingkat pendidikan merupakan faktor resiko ketidakpatuhan dengan nilai $p$ sebesar 0,536 $(p>0,05)$ dan jenis kelamin juga merupakan faktor resiko ketidakpatuhan dengan nilai $p$ sebesar 0,068 ( $p>0,05)$. Kata kunci: Epilepsi, Kepatuhan, Faktor resiko
\end{abstract}

\begin{abstract}
Epilepsy is one of the most common brain diseases in the world. World Health Organization (WHO) data shows that epilepsy affects 70 million of the world's population. Chronic disease is a disorder or disease that lasts for a long time (months or years), such as hypertension, diabetes mellitus, leprosy, epilepsy, tuberculosis, AIDS, leukemia, and so on. This study aims to determine the relationship between the level of adherence to taking medication with gender and education level on the incidence of epilepsy with the use of antihepileptic drugs in epileptic patients at the outpatient installation of Citra Sari Husada Intan Barokah Hospital, Karawang period August-November 2020. This study is observational. by using a cross-sectional descriptive analysis design. Data collection was carried out prospectively and retrospectively using secondary data in the form of epilepsy patient prescriptions and primary data in the form of questionnaires given to outpatients at Citra Sari Husada Intan Barokah Hospital, Karawang period August-November 2020. This research was conducted by distributing questionnaires to respondents. who have met the inclusion criteria. Data obtained were 96 epilepsy patients who became respondents. The results of this study indicate that education level is a risk factor for non-compliance with a $\mathrm{p}$ value of $0.536(\mathrm{p}>0.05)$ and gender is also a risk factor for noncompliance with a $\mathrm{p}$ value of 0.068 ( $\mathrm{p}>0.05)$.
\end{abstract}

Keywords: Epilepsy, Obedience, Risk factor 


\section{PENDAHULUAN}

E ISSN : 2580-5517

Epilepsi merupakan salah satu penyakit otak yang sering ditemukan di dunia. Data World Health Organization (WHO) menunjukkan epilepsi menyerang 70 juta dari penduduk dunia. Epilepsi ditandai oleh bangkitan berulang (paling sering dalam manifestasi kejang) yang diakibatkan oleh aktivitas listrik yang berlebihan pada sebagian atau seluruh bagian otak. Bangkitan epilepsi disebabkan oleh ketidakseimbangan antara faktor eksitasi dan inhibisi cerebral, bangkitan akan muncul pada eksitabilitas yang tidak terkontrol. Pada sebagian besar kasus tidak dijumpai kelainan anatomi struktural otak. Namun pada beberapa kasus, epilepsi disertai dengan kerusakan struktural otak yang mengakibatkan disfungsi fisik dan retardasi mental (WHO, 2001).

Menurut WHO, kurang lebih 50 juta orang di seluruh dunia mengidap epilepsi. Epilepsi bisa terjadi pada siapa saja di seluruh dunia tanpa batas ras serta sosial ekonomi. Pendataan yang dilakukan secara global dijumpai 3,5 juta kasus baru per tahun antara lain 40\% merupakan kanak- kanak serta dewasa kurang lebih $40 \%$ dan $20 \%$ yang lain ditemui pada usia lanjut (WHO, 2001; Fosgren, 2001). Angka kejadian epilepsi masih tinggi paling utama di negara berkembang yang menggapai 114 per 100.000 penduduk per tahun. Angka tersebut terkategori tinggi dibandingkan dengan negara yang maju dimana angka peristiwa epilepsi berkisar antara 24-53 per 100.000 penduduk per tahun (Benerjee and Sander, 2008). Kasus epilepsi di Indonesia berjumlah sedikitnya 700.000-1.400.000 kasus dengan pertambahan sebesar 70.000 kasus baru tiap tahun serta diperkirakan kurang lebih 40-50\% dari prevalensi tersebut berlangsung pada anak-anak (Suwarba, 2011).

Mutu hidup yang berhubungan dengan kesehatan menggambarkan totalitas keadaan status kesehatan seseorang pasien, termasuk kesehatan fisik pasien, sosial, psikologis, serta ekonomi pasien. Evaluasi mutu hidup dipengaruhi oleh kondisi fisik, mental, sosial, serta emosional. Seseorang penderita dengan epilepsi bisa dinilai kualitas hidupnya bersumber pada salah satu aspek yakni lama menderita epilepsi (Duration of epilepsy). Dalam melakukan penilaian kualitas hidup pada penderita epilepsi dapat menggunakan suatu instrumen yaitu, Quality of Life in Epilepsy (Qolie) Penyakit kronis adalah gangguan atau penyakit yang berlangsung lama (berbilang bulan atau tahun). Contohnya hipertensi, diabetes melitus, kusta, epilepsi, TBC, AIDS, leukimia, dan sebagainya. Agar proses kesembuhan pasien yang mengidap penyakit kronis segera terwujud, kerja sama antara pasien serta keluarganya dengan penyedia layanan kesehatan, khususnya dokter harus terjalin dengan baik. Ketidakpatuhan minum obat dapat dilihat terkait dengan dosis, cara minum obat, waktu minum obat dan periode minum obat yang tidak sesuai dengan aturan. Jenis-jenis ketidakpatuhan meliputi 
Maulana Yusuf Alkandahri, Isra Qurrata Ayun Eka Putri

Vol. 5 No 2

ISSN : 2541-6995

E ISSN : 2580-5517

ketidakpatuhan yang disengaja (intentional non compliance) dan ketidakpatuhan yang tidak disengaja (unintentional non compliance). Ketidakpatuhan yang disengaja (intentional non compliance) disebabkan karena keterbatasan biaya pengobatan, sikap apatis pasien, dan ketidakpercayaan pasien akan efektivitas obat. Ketidakpatuhan yang tidak disengaja

(unintentional non compliance) karena pasien lupa minum obat, ketidaktahuan akan petunjuk pengobatan, kesalahan dalam hal pembacaan etiket (Edefonti et al., 2011).

Faktor- faktor yang mempengaruhi tingkatan kepatuhan merupakan segala sesuatu yang bisa berpengaruh positif sehingga pasien tidak dapat lagi mempertahankan kepatuhannya, hingga menjadi kurang patuh serta tidak patuh. Ada pula faktor- faktor yang mempengaruhi kepatuhan antara lain merupakan kualitas interaksi antara petugas kesehatan dengan pasien, jenjang pendidikan, serta tingkatan pengetahuan (Astuti, 2017). Faktor efek yang mempengaruhi ketidakpatuhan minum obat diantaranya adalah usia pasien, anggaran obat yang mahal, tidak bisa mengatur tekanan pikiran, kualitas pelayanan kesehatan, serta pengobatan dalam jumlah banyak (Astuti, 2017). Berdasarkan permasalahan latar belakang di atas, maka peneliti ingin melakukan penelitian dengan tujuan untuk mengetahui kepatuhan penggunaan obat fenitoin pada pasien epilepsi sehingga penelitian ini diharapkan dapat bermanfaat bagi pasien tersebut, terutama dalam hal keberhasilan dalam pengobatan.

\section{METODE PENELITIAN}

\section{Objek Penelitian}

Pasien epilepsi yang menerima obat fenitoin yang ada di Rumah Sakit Citra Sari Husada Intan Barokah Karawang periode Agustus-November 2020.

\section{Pengumpulan Data}

1. Kriteria Inklusi

a. Usia $\geq 18$ tahun

b. Bersedia menjadi responden

c. Pasien yang sedang menggunakan terapi obat fenitoin

2. Kriteria Eksklusi

a. Mempunyai gangguan psikis

b. Tenaga kesehatan (dokter, perawat, bidan, apoteker)

c. Sudah pernah mengisi kuesioner penelitian ini.

Populasi penelitian ini adalah data pasien yang berbat ke poli saraf di Rumah Sakit Citra Sari Husada Intan Barokah Karawang. Sampel dari penelitian ini adalah pasien yang memenuhi 
kriteria inklusi. Pengambilan sampel berasal dari hasil observasi data menggunakan instrument penelitian berupa kuesioner tentang kepatuhan penggunaan obat fenitoin pada pasien epilepsi, dengan menggunakan teknik random sampling yaitu teknik penentuan sampel dengan pertimbangan tertentu yang memenuhi kriteria inklusi. Penetapan jumlah sampel pada penelitian ini menggunakan rumus Lameshow (1997) sebagai berikut :

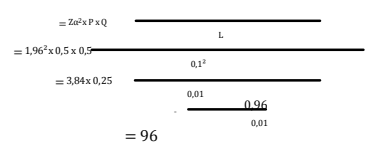

Keterangan :

$\begin{array}{ll}\mathrm{n} & \text { : Jumlah sampel minimal yang diperlukan } \\ \mathrm{Z} \alpha & : \text { Nilai standar dari distribusi sesuai nilai } \alpha \\ \mathrm{P} & : \text { Prevalensi outcome } \\ \mathrm{Q} & : 1-\mathrm{P} \\ \mathrm{L} & : \text { Tingkat ketelitian }\end{array}$

\section{Instrumen Penelitian}

Penelitian ini menggunakan instrument penelitian berupa kuesioner MMAS-8. Data dikumpulkan dengan menggunakan kuesioner yang telah diuji validitas dan reliabilitasnya, isi pertanyaan pada kuisioner tidak diubah namun tampilan pada kuesioner dibuat lebih menarik agar responden tertarik untuk ikut serta dalam penelitian ini, kuesioner diambil dari penelitian terdahulu. Data yang diperoleh dalam penelitian ini diolah dengan menggunakan Microsoft Office Excel 2016 untuk mengetahui hasilnya, penyajian data dalam penelitian ini menggunakan tabel untuk mengetahui gambaran tingkat kepatuhan oleh pasien epilepsi di salah satu Rumah Sakit Citra Sari Husada Intan Barokah Karawang.

Penilaian angka kepatuhan terkait pada terapi farmakologi dengan kuesioner morisky 8item parameter penilaian tertentu yang telah tervalidasi adalah pengukuran skor Morisky Scale 8Item untuk pertanyaan 1 sampai dengan 7, kecuali pertanyaan nomer 5 jawaban ya bernilai 1 , sedangkan pertanyaan nomer 8 jika menjawab tidak pernah /jarang (tidak sekalipun dalam 
satu minggu) bernilai nol dan bila responden menjawabsesekali (satu/dua kali dalam satu minggu), terkadang (tiga/empat kali dalam satu minggu) dan setiap selalu bernilai 1. Pasien dengan total skor lebih dari dua dikatakan tingkat kepatuhannya rendah, jika skor 1 atau 2 dikatakan tingkat kepatuhannya sedang, dan jika skor 0 dikatakan responden memiliki tingkat kepatuhan yang tinggi.

\section{Analisis Data}

Pada penelitian ini dilakukan analisis data untuk mengetahui kepatuhan penggunaan obat fenitoin pada pasien epilepsi dengan metode korelasi chi square menggunakan program SPSS.

\section{HASIL PENELITIAN DAN \\ PEMBAHASAN Hasil Penelitian}

Hasil penelitian ini merupakan penelitian analitik yang bersifat observasional secara Cross Sectional dan pengambilan data secara prospektif. Sampel penelitian yang digunakan sebanyak 96 pasien. Pengambilan sampel menggunakan teknik Purposive Random Sampling dimana utnuk melihat gambaran tingkat kepatuhan minum obat fenitoin pada pasien epilepsi dari Poli Saraf di Rumah Sakit Citra Sari Husada Intan Barokah Karawang menggunakan kuesioner MMAS-8.

Pada penelitian ini dilakukan uji validitas konstruk dan reliabilitas pada kuesioner MMAS8. Hasil analisa menunjukkan bahwa kuesioner MMAS-8 yang digunakan valid dengan $r$ hitung semua butir pertanyaan $>\mathrm{r}$ tabel. Berdasarkan tabel $\mathrm{R}$ pearson dapat dilihat $\mathrm{N}$

= 96 dengan signifikansi 5\% didapatkan $\mathrm{r}$ tabel sebesar 0,201. Pada tabel correlation yang merupakan output dari SPSS akan diketahui R. Hitung pada baris pearson correlation tiap item $P$ Instrumen dinyatakan reliabel apabila koefisien reliabilitas Alpha Cronbach $>0,6$ (Siregar, 2013). Pada tabel realibility Statistics terlihat bahwa nilai Cronbach's Alpha sebesar 0,733 untuk 8 item pernyataan >0,60 maka dapat disimpulkan bahwa seluruh pernyataan dalam angket reliabel atau konsisten.

Dari penelitian diperoleh data demografi responden yaitu jenis kelamin dan tingkat pendidikan pasien. Responden berjenis kelamin laki-laki sebanyak 50 pasien $(52,1 \%)$ dan berjenis kelamin perempuan sebanyak 46 pasien (47,9\%). Prevalensi penyakit epilepsi cenderung terjadi pada laki-lakidaripada perempuan. Jumlah repsonden paling banyak berada pada tingkat pendidikan SMA/SMK sebesar 64 pasien (66,7\%), SMP sebesar 18 pasien $(18,8 \%)$ dan terdapat 14 pasien $(14,5 \%)$ dengan tigkat pendidikan SD. 
Tabel 1. Karakteristik jenis kelamin pasien epilepsi rawat jalan di poli saraf di Rumah Sakit Citra Sari Husada Intan Barokah Karawang periode Agustus-November 2020.

\begin{tabular}{cc}
\hline Jenis Kelamin & n (\%) \\
\hline Laki-laki & $50(52,1 \%)$ \\
Perempuan & $46(47,9 \%)$ \\
\hline Jumlah & $96(100 \%)$ \\
\hline
\end{tabular}

Tabel 2. Karakteristik tingkat pendidikan pasien epilepsi rawat jalan di poli saraf di Rumah Sakit Citra Sari Husada Intan Barokah Karawang periode Agustus-November 2020.

\begin{tabular}{cc}
\hline Tingkat Pendidikan & n (\%) \\
\hline SD & $14(14,5 \%)$ \\
SMP & $18(18,8 \%)$ \\
SMA/SMA & $64(66,7 \%)$ \\
\hline Jumlah & $96(100 \%)$ \\
\hline
\end{tabular}

Tabel 3. Kepatuhan pasien dengan metode MMAS-8.

\begin{tabular}{ccc}
\hline Skor Kepatuhan & Kategori & $\mathbf{n}(\boldsymbol{\%})$ \\
\hline$>2$ & Rendah & $46(47,9 \%)$ \\
$1-2$ & Sedang & $41(42,7 \%)$ \\
0 & Tinggi & $9(9,4 \%)$ \\
\hline
\end{tabular}

Tabel 4. Kolerasi faktor resiko tingkat pendidikan dengan tingkat kepatuhan pada pasien epilepsi di salah satu Rumah Sakit Citra Sari Husada Intan Barokah Karawang periode Agustus-November 2020.

\begin{tabular}{|c|c|c|c|c|c|c|c|}
\hline \multirow{3}{*}{$\begin{array}{c}\text { Katagori } \\
\text { Tingkat } \\
\text { Pendidikan }\end{array}$} & \multicolumn{4}{|c|}{ Tingkat Kepatuhan } & \multirow{2}{*}{\multicolumn{2}{|c|}{ Total }} & \multirow{3}{*}{$p$ value } \\
\hline & \multicolumn{2}{|c|}{ Patuh } & \multicolumn{2}{|c|}{ Tidak patuh } & & & \\
\hline & Jumlah & $\%$ & Jumlah & $\%$ & Jumlah & $\%$ & \\
\hline $\mathrm{SD}$ & 5 & 17,2 & 9 & 13,4 & 14 & 16 & \\
\hline SMP & 7 & 24,1 & 14 & 16,4 & 5 & 5 & \\
\hline SMA / SMK & 17 & 58,7 & 47 & 70,2 & 76 & 78 & 0,536 \\
\hline Total & 9 & 100 & 87 & 100 & 96 & 100 & \\
\hline
\end{tabular}


Tabel 5. Kolerasi faktor resiko jenis kelamin dengan tingkat kepatuhan pada pasien epilepsi di salah satu Rumah Sakit Citra Sari Husada Intan Barokah Karawang periode Agustus-November 2020.

\begin{tabular}{|c|c|c|c|c|c|c|c|}
\hline \multirow{3}{*}{ Karakteristik } & \multicolumn{4}{|c|}{ Tingkat Kepatuhan } & \multirow{2}{*}{ Total } & & \multirow{2}{*}{$\begin{array}{c}P \\
\text { value }\end{array}$} \\
\hline & \multicolumn{2}{|l|}{ Patuh } & \multicolumn{2}{|c|}{ Tidak Patuh } & & & \\
\hline & Jumlah & $\%$ & Jumlah & Jun & ah\% & & \\
\hline Perempuan & 18 & 62,1 & 28 & 41,8 & 46 & 47,9 & \\
\hline Laki-laki & 11 & 37,9 & 39 & 58,2 & 50 & 52,1 & U,008 \\
\hline Total & 29 & 100 & 67 & 100 & 96 & 100 & \\
\hline
\end{tabular}

\section{Pembahasan}

Pada Tabel 1 tampak bahwa pasien yang menderita penyakit epilepsi lebih banyak adalah laki-laki dengan jumlah 50 pasien $(52,1 \%)$ sedangkan perempuan seabanyak 46 pasien (47,9\%). Tingkatan insidensi epilepsi menunjukkan laki-laki lebih sering terjangkit daripada perempuan. Menurut Calisir et al (2006) tingkatan insidensi pada pria lebih besar merupakan kontribusi faktor efek dari trauma kepala. Berdasarkan jenis kelamin, ditemukan bahwa insidensi epilepsi pada laki-laki lebih tinggi daripada perempuan. Sementara itu, pada Tabel 2 menunjukkan bahwa pasien yang berobat epilepsi dengan tingkat pendidikan SMA/SMK lebih banyak yaitu 64 pasien $(66,7 \%)$, SMP sebanyak 18 pasien $(18,8 \%)$ dan tingkat pendidikan SD lebih sedikit yaitu sebanyak14 pasien (14,5\%). Faktor resiko terjadinya epilepsi sangat beragam, di antaranya adalah infeksi Sistem Saraf Pusat, trauma kepala, tumor, dan penyakit degeneratif. Meskipun terdapat bermacam-macam faktor resiko tetapi sekitar $60 \%$ kasus epilepsi tidak dapat ditemukan penyebab yang pasti.

Dari hasil Tabel 3 terlihat bahwa tingkat kepatuhan yang tinggi sangat sedikit yaitu sebanyak 9 responden $(9,4 \%)$. Banyak faktor yang mempengaruhi kepatuhan pasien dalam menjalankan terapinya, yaitu faktor pasien, faktor penyakit, faktor regimen terapi, dan faktor interaksi dengan praktisi kesehatan. Faktor pasien, meliputi faktor keterbatasan dari fungsional tubuh pasien, dengan bertambahnya umur, fungsi fisiologis mengalami penurunan akibat degeneratif (penuaan). Pada penelitian ini pasien mendapatkan obat dengan etiketnya beserta penjelasan penggunaan obatnya. Beberapa pasien mengganti aturan pakai obat. Berbagai macam alasan diantaranya adalah rasa bosan jika terus menerus mengkonsumsi obat. Faktor penyakit adalah faktor yang mempengaruhi kepatuhan pasien. Epilepsi adalah penyakit kronis yang membutuhkan terapi jangka panjang yang dapat menyebabkan ketidakpatuhan pasien. Pemberian obat anti epilepsi ini bertujuan untuk mengontrol bangkitan epilepsi. 
Beberapa cara yang dapat digunakan untuk meningkatkan kepatuhan pasien adalah dengan mengatasi faktor-faktor. Untuk mengatasi faktor pasien sendiri dapat dilakukan dengan memberikan pengetahuan yang cukup mengenai obat yang dikonsumsi pasien tersebut. Hal ini dapat dilakukan saat apoteker menyampaikan informasi dan melakukan konseling kepada pasien saat penyerahan obat. Informasi yang harus disampaikan meliputi dosis, bentuk sediaan, rute dan metoda pemberian, farmakokinetik, farmakologi, terapetik dan alternatif, efikasi, keamanan penggunaan pada ibu hamil dan menyusui, efek samping, interaksi, stabilitas, ketesediaan, harga, sifat fisika atau kimia dari obat. Sedangkan konseling merupakan proses interaksi antara apoteker dengan pasien untuk meningkatkan pengetahuan, pemahaman, kesadaran, dan kepatuhan pasien (Depkes, 2014). Dengan adanya informasi yang berulang-ulang diharapkan dapat diterima dan diingat oleh pasien.

Berdasarkan Tabel 4 dapat dilihat tingkat kepatuhan pasien epilepsi kategori patuh pada tingkat pendidika SD sebanyak 5 pasien (17,2\%), pada tingkat pendidikan SMP sebanyak 7 pasien $(24,1 \%)$, dan pada tingkat pendidikan SMA/SMK sebanyak 17 pasien $(58,7 \%)$, sedangkan untuk kategori tidak patuh pada tingkat pendidikan SD sebanyak 9 pasien $(13,4 \%)$, pada tingkat pendidikan SMP sebanyak 14 pasien (16,4\%), pada tingkat pendidikan SMA/SMK sebanyak 47 pasien (70,2\%). Pada analisa Chis Square nilai $p$ sebesar 0,536 ( $p>$ $0,05)$ pada hasil penelitian ini tingkat pendidikan bukan faktor risiko ketidakpatuhan. Hal ini sejalan dengan penelitian yang dilakukan oleh Tisna (2009) melaporkan bahwa faktor pendidikan dan pengetahuan tidak memiliki hubungan yang signifikan terhadap tingkat kepatuhan pasien dalam minum obat. Semakin lama seseorang menderita epilepsi maka tingkat kepatuhanya makin rendah, hal ini disebabkan kebanyakan penderita akan merasa bosan untuk berobat. Semakin lama seseorang menderita epilepsi maka cenderung untuk tidak patuh karena merasa jenuh menjalani pengobatan atau meminum obat sehingga tingkat kesembuhan yang telah dicapai tidak sesuai dengan yang diharapkan.

Berdasarkan Tabel 5 dapat dilihat tingkat kepatuhan pasien dikategorikan menjadi 2 kategori yaitu kategori patuh dan tidak patuh. Jumlah pasien yang patuh sebanyak 29 pasien $(30,2 \%)$ dan yang tidak patuh sebanyak 67 pasien (69,8\%). Sehingga angka ketidakpatuhan lebih tinggi dibandingkan dengan angka kepatuhan. Berdasarkan penelitian Hayers, et al (2009) menunjukkan bahwa pada berbagai penyakit kronis, pasien yang tergolong tidak patuh dalam mengkonsumsi obat lebih dari 50\%, bahkan dalam penelitian Jarbose (2002) menunjukkan bahwa pasien yang tidak patuh pada akhirnya akan diikuti dengan berhentinya pasien untuk mengkonsumsi obat. Ketidakpatuhan minum obat dapat dilihat terkait dengan dosis, cara minum obat, waktu minum obat dan periode minum obat yang tidak sesuai dengan 
Maulana Yusuf Alkandahri, Isra Qurrata Ayun Eka Putri

Vol. 5 No 2

ISSN : 2541-6995

E ISSN : 2580-5517

aturan. Kategori patuh pada jenis kelamin laki-laki sebanyak 11 pasien $(37,9 \%)$ dan perempuan sebanyak 18 pasien $(62,1 \%)$. Sedangkan untuk kategori tidak patuh pada laki-laki sebanyak 39 pasien $(58,2 \%)$ dan perempuan sebanyak 28 pasien $(41,8 \%)$. Pada analisa Chi-Square didapatkan nilai $p$ value sebesar 0,068 $(p>0,05)$ pada penelitian ini jenis kelamin merupakan faktor resiko ketidakpatuhan. Hal ini sejalan dengan penelitian yang dilakukan oleh Alphonce (2012) yang menunjukan jenis kelamin berhubungan dengan tingkat kepatuhan pengobatan.

Dalam hal menjaga kesehatan biasanya perempuan lebih memperhatikan kesehatanya dibandingkan dengan laki-laki.

\section{KESIMPULAN}

1. Tingkat kepatuhan minum obat antiepilepsi pada pasien epilepsi dari poli saraf di Rumah Sakit Citra Sari Husada Intan Barokah karawang masih rendah.

2. Pada hasil analisis uji Chi-Square dari penelitian ini menunjukkan bahwa tingkat pendidikan merupakan faktor resiko ketidakpatuhan dengan nilai $p$ sebesar 0,536 $(p>0,05)$ dan menunjukkan bahwa jenis kelamin merupakan faktor resiko ketidakpatuhan dengan nilai $p$ sebesar 0,068 $(p>0,05)$.

\section{SARAN}

1. Perlu adanya penelitian selanjutnya mengenai analisis kepatuhan minum obat terhadap tingkat keberhasilan terapi obat pada pasien.

2. Perlu adanya penelitian lanjutan tentang analisa kepatuhan minum obat fenitoin pada pasien epilepsi dari poli saraf di Rumah Sakit Citra Sari Husada Intan Barokah Karawang dengan sampel yang lebih banyak.

\section{DAFTAR PUSTAKA}

Alphonce, A. (2012). Factors Affecting Treatment Compliance Among Hypertension Patients In Three District Hospitals - Dar Es Salaam. Disertasi: Universitas Muhimbili.

Astuti, Y. (2017). Faktor-Faktor yang Berhubungan Dengan Kepatuhan Penderita Kusta Untuk Datang Berobat Teratur di Wilayah Jakarta Selatan Tahun 2014. Jurnal Ilmiah WIDYA, 4(2), 262-267.

Benerjee, P.N. and Sander, J.W. (2008). Incidence and Prevalence. Epilepsy A Comprehensive Textbook ${ }^{2 n d}$ edition. Lippincott Williams \& Wilkins. pp: 45-56.

Calisir, N., Bora, I., Irgil, E., Boz, M. (2006). Prevalence of Epilepsy in Bursa City Center, an Urban Area of Turkey. Epilepsia, 47, 1691-99. 
Departemen Kesehatan RI. (2014). Peraturan Menteri Kesehatan Republik Indonesia Nomor 35 Tahun 2014 tentang Standar Pelayanan Kefarmasian di Apotek. Jakarta: Direktorat Jenderal Bina Kefarmasian dan Alat Kesehatan RI.

Edefonti, V., Bravi, F., Turner, K., Beghi, E., Canevini, M.P., Ferraroni, M., and Piazzini, A. (2011). Health-related quality of life in adults with epilepsy: the effect of age, age at onset, duration of epilepsy in a multicentre italian study. BMC Neurology, 11:33.

Fosgren, L. (2001). Epidemiology of Epilepsy: a Global Problem. Program and Abstracts of the $17^{\text {th }}$ Wrold Congress of Neurology. J Neurol Sci, 187(Suppl 1): S212.

Hayers, T. L., Larimer, N., Adami, A. and Kaye, A. (2009). Medication Aherence in Healthy Elders: Small Cognitive Change Make a Big Differences. Journal of Aging \& Health. 21 (4), 567-580.

Jarbose, K.S. (2002). Treatment Nonadherence: Cases and Potential Resolutions. Journal of American Psychiatric Nurses Association, 8(4), 18-25.

Lemeshow. (1997). Besar Sampel Dalam Penelitian Kesehatan. Jogjakarta. Gadjah Mada University Press.

Siregar, S. (2013). Metode Penelitian Kuantitatif. Jakarta: Kencana Prenadamedia Group.

Suwarba, I.G.N.M. (2011). Insidens dan Karakteristik Klinis Epilepsi pada Anak. Sari Pediatri, 13(2), 123-128.

Tisna, N. (2009). Faktor-Faktor Yang Berhubungan Dengan Tingkat Kepatuhan Pasien Dalam Minum Obat Antihipertensi. http://perpus.fkik.uinjkt.ac.id/filedow nload/Nandang\%20Tisna.pdf. Diakses tanggal 26 Desember 2020.

WHO. (2001). Epilepsy: Social Consequences and Economic Aspects, WHO Fact Sheet No, 166. 